\title{
AN ANALYSIS OF ADHD CHILD ACCIDENT INCIDENT RATES IN THE SCHOOL ENVIRONMENT
}

\section{LUCIE DONČEVOVÁ}

University of South Bohemia in České Budějovice (doctoral studies)

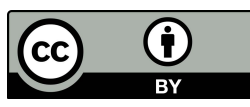
Faculty of Health and Social Sciences, J. Boreckého 1167/27 České Budějovice

The University Jan Evangelista Purkyně in Ústí nad Labem Faculty of Health Studies Department of Occupational Therapy, Velká Hradební 13, Ústí nad Labem 40096 E-mail address: lucie.doncevova@ujep.cz

\begin{abstract}
Aim. The main objective of this article is to contribute to the research in the area of accident incident rates among school children.

Methods. A non-standardized, 12-item questionnaire based on independent compilation was used for data collection. The questionnaire contained closed questions which monitor the nature of school-related injuries, gender and age of respondents.

Results. 100 students with diagnosed ADHD and 100 children without ADHD diagnosis participated in the research. The accident and incident data were collected between September 2016 and June 2017. Out of 100 given questionnaires filled by ADHD children, the result shows that $49 \%$ of them experienced an injury in school and children without ADHD diagnosis reported injury in only $26 \%$ of cases, which means that roughly every second child with a Attention Deficit Hyperactivity Disorder experienced an injury some time during the school year during class, whereas among neurotypical children this ratio would refer to every fourth child.

Conclusions. The results of the analysis pointed at the possible need of informing all staff involved in the education system of ADHD children about the risks of injury in school environment and thus support the prevention of injuries, support the prevention programs which would be focused on children with attention disorders.

Key words: Attention Deficit Hyperactivity Disorder, disability, inclusive educa-
\end{abstract} tion, prevention, injury

\section{INTRODUCTION}

The occurrence of ADHD among the child population is estimated to be $3-5 \%$; some authors are stating that up to $10 \%$ of all child school populations are diagnosed with ADHD today. The probability of ADHD is greater in males than females (most commonly cited ratio being 6:2). The criteria for ADHD dia- 
gnostics is described by Diagnostic and Statistical Manual of Mental Disorders, DSM-5, Czech sources include diagnostics in the international disease classification document in the hyperkinetic disorders chapter. Since the end of 2013 three elementary ADHD subtypes are being distinguished by the DSM-5. First type of ADHD is the attention deficit (previously defined as ADD), second is the hyperactive and impulsive type and third is the combined type. Children with attention deficit disorders are easily distracted by external stimuli. ADHD children also have trouble concentrating on a specific task and also with its finishing. Their study skills are not sufficient and are not able to work independently. Typical manifestations of such issues is the low attention span. The child is then easily drained of energy and is not able to do one activity or over a longer period of time.

Main symptoms of ADHD (Attention Deficit Hyperactivity Disorder) are attention span disruptions, hyperactivity and impulsiveness. Such tirades are however not the only manifestation of attention deficit disorder. Aside from these elementary symptoms, hyperactive children also manifest symptoms of related disorders, which are closely connected to the attention deficit disorder. These include mainly the perceptual and motor function disorders, principally in the area of visual and auditory perception. We may also observe cognitive function disorders which relate to the memory function (mainly the working memory), that is closely related to concentration disorders among children with ADHD - all of the previously mentioned aspects are related to impulsiveness and perceptual and motor disorders (Jucovičová, \& Žáčková, 2010). Most children are diagnosed with ADHD during the first 9 years of compulsory primary education, specifically between $6^{\text {th }}$ and $9^{\text {th }}$ grade. At the beginning of primary school education a lot of pressure is being put on children and thus they are confronted with each other, out of which we may observe social relations between students in class. In such an environment is impossible to overlook concentration and focus issues among individuals.

M. Goetz and P. Uhlíková (2009) say, that a child's ADHD symptoms are gradually increasing in intensity after the initiation into primary school. The injury risk is then caused due to the non-structured time schedule e.g. during breaks between classes. Children have to control their behaviour themselves during breaks without any supervision of an adult which may cause problems (Goetz \& Uhlíková, 2009). The transition into another classroom, transport from the gym class into the locker rooms, lunch breaks, waiting for the school bus to pick children up and many other situations need social behaviour, which these children do not control well (Goetz, \& Uhlíková, 2009; Wolfdieter, 2013). Studies abroad focused on the injury analysis of children with different disability types proved a significantly higher prevalence of injury among children with ADD (ADHD compared with children with no disability (Xiang, Stallones, Chen, Hostetler, \& Kelleher, 2005). A similar study titled: Increased risk injury in children with developmental disabilities; compared six groups of children ages 3-5. The results of the study supported the theory that ADD/ADHD children, autistic children and children with behavioural disorders had twice or 
even three times higher amount of experience of getting hurt during the school day than other children in the control group. The concluding part of the research pointed at the necessity of analysing the injury characteristics according to the specific type of disorder, which may uncover individual differences in the properties of specific injury types. Research in this area can help create specific preventive measures in the future (Xiang, Stallones, Chen, Hostetler, \& Kelleher, 2005; Lee, Harrington, Chan, \& Connors, 2008).

\section{METHODOLOGY}

In order to process the theoretical outcomes of the study, a source research method was chosen for providing enough data. Searching through available sources provided complex information related to the Accident incident rates of ADHD children and children with other types of disabilities. A non-standardized questionnaire based on individual compilation which included 14 questions was used for data collection. The questions were closed and their content monitored the nature of school-related injuries, gender and age of the respondents. The questionnaire was anonymous and filling-in was voluntary. Previously mentioned studies regarding Accident incident rates of children with physical disabilities proved mainly the insufficient amount of data necessary for making satisfactory conclusions. Even after admitting that this topic is becoming more and more current not only in the Czech Republic, but also in European publications, nothing much has been said about the nature, causes and prevention in this area. As mentioned previously, children with disabilities represent an at risk group inside the school environment. In the Czech Republic this topic is well discussed mainly from the point of view of inclusive education reform. Information about the injury patterns inside the school environment can help schools understand and better fulfil the educational goals. One such goal is to help children with disabilities learn skills necessary for social and physical integration into a specific community. In order to integrate a child with specific educational needs does not mean only to place the child into a normal school environment or to ensure organisational conditions, but to provide enough support and service the child needs and for which he or she has the legal right in the same way as other students.

There are a lot of injuries reported in schools mainly because school children spend the major part of the day in school premises. Injuries happen not only in class, but during breaks, lunch breaks, also on the way from and to school. Children with psychical disabilities are then more likely to sustain an injury than other children due to the decreased ability to control motion and motor skills, other mental disorders, or due to side effects of medication (Zhu, Xia, Xiang, Yu, \& Du, 2012; Ramirez, Fillmore, Chen, \& Peek-Asa, 2012; Watier, 2016). Teachers and therapists role as part of the injury prevention is to support the correct psychomotor development of children who are able then to gain more sensory and motor experience. Furthermore teachers and therapists 
contribute to the creation of safe school environment by e.g. classroom modification (eliminating sharp edges of furniture, anti-slip floor modifications etc.).

Efficient and focused prevention is necessary to analyse at first the current state of the problem. The research in this area has already given data about the injury structure and circumstance of origin among children with attention deficit disorders. Information related to the school injury structure can help the integration process of children into the in-and-out school environment. By creating safe school environment relating the type and degree of a disorder or disability, schools can then better fulfil the educational goals. For the purpose of our research we defined our goal, which is to contribute to the solutions of accident incident rates among children with attention deficit disorders inside the school environment. The main goal was to collect data of accident incident rates in public schools of the Czech Ústí nad Labem region via a questionnaire method. We successfully analysed and divided the data according to age, gender, injury type, place, activity, mechanisms, localisation and degree of injury. The analysis then continued with a comparison of injury structure between ADD/ ADHD children and non-diagnosed children in the control group.

The research question was, as follows: What are the Accident incident rates of children with attention deficit disorders in comparison with non-diagnosed children in public elementary schools? We also established a working hypothesis: The risk of accidents in the school environment will differ between children with attention deficit disorders and normal children. The first phase of the research included contacting school principals and authorities in Ústí nad Labem region to help with the research realisation. The schools were randomly selected to create a random data sample. The data collection was then done by individual school teachers. Teachers, who were willing to join the initiative, helped and collaborated and were given a financial reward. The basic data sample consisted mainly of children with attention deficit disorder who attended 9-year elementary school programs The data sample also included a control group of children with no learning disability diagnosis. Both male and female respondents are represented in the overall data sample. The age of the children ranged from 10-15 years.

Children from the second elementary stage (lower primary $4^{\text {th }}-5^{\text {th }}$ grade in Czech school system) and second elementary stage (lower secondary $6^{\text {th }}$ to $9^{\text {th }}$ grade) were selected intentionally due to the reliability of ADD/ADHD diagnostics at this particular stage of psychological development. We then separated into two categories: children with and without ADHD diagnosis. Children in the ADHD group were selected intentionally and reflected the set criteria (attention deficit disorder diagnosed by psychologist). Totally, 100 children with ADHD are included in the data sample, out of which 49 reported injury. The second group, children with no diagnosis who were again intentionally selected by selecting the first 10 names in the class list. Overall, 11 primary schools offered respondents to participate in the research. A questionnaire method was selected - the questionnaire itself then contained closed, semi-closed and multiple choice questions, which made it possible to make content analysis of the gained data. After data collection, statistical data analysis 
helped to give percentages of occurrence. For better data evaluation, chi-square test of contingency table was used. Because of the non-parametric data sample Wilcoxon pair test was used which evaluated the difference in data statistically significant.

\section{RESULTS}

In order to interpret the gained data, comparison can show the amount of injuries of ADHD and regular children. Data about the sustained injuries related the time period between September 9, 2016 and June 30, 2017. Out of 100 questionnaires filled-in by ADHD children, 49 reported injury, only 26 regular children reported sustained injury, which means that approximately every second child with ADHD has sustained an school-related injury, whereas one in four regular children sustained and injury, showing a dramatic disproportion of injury probability. The results of this analysis can be seen in the following table and graph 1.

Table 1. Injury rates of ADHD and intact children compared ( $\mathrm{p}$-value $=0$, 00078122)

\begin{tabular}{lccc}
\hline \multicolumn{4}{c}{ Contingency table of empirical frequency } \\
\hline Category & ADHD & without ADHD & Total \\
without injury & 51 & 74 & 125 \\
experienced injury & $\mathbf{4 9}$ & $\mathbf{2 6}$ & 75 \\
Total & 100 & 100 & 200 \\
\hline
\end{tabular}

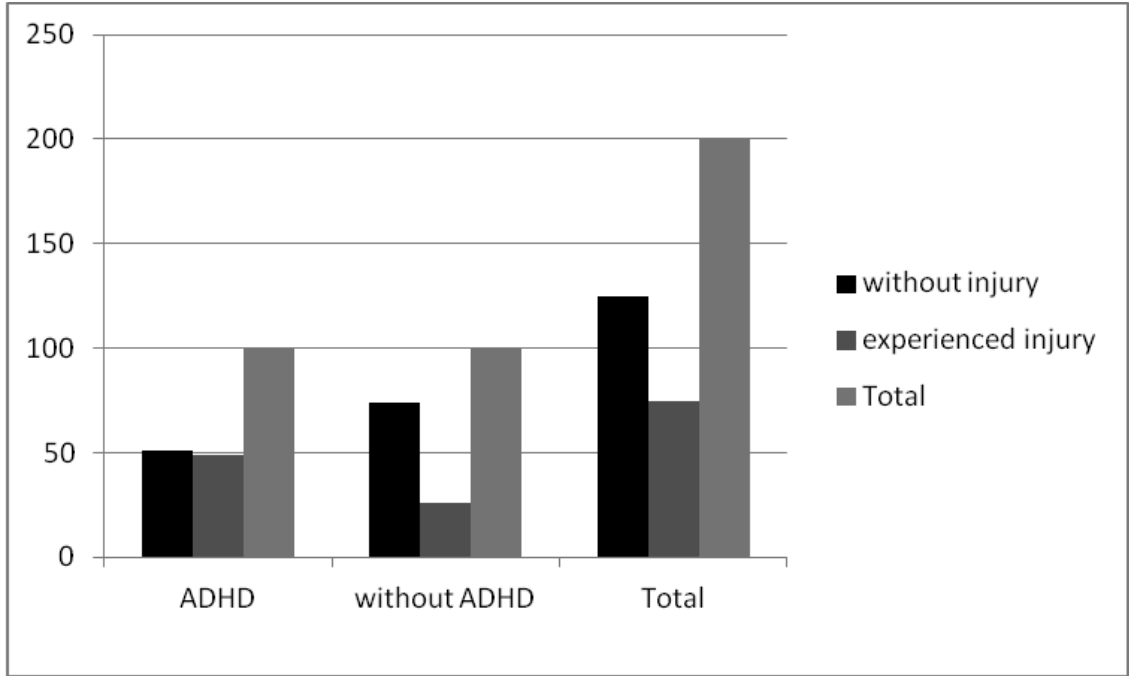

Graph 1. Injury rates of ADHD and intact children compared 


\section{DISCUSSION}

Chidren spend the majority of their day time at school so naturally a greater amount of injuries occur during school time. Injuries happen not only in classes, but also during breaks, lunch breaks, on the way in and out of school. The Czech school inspection reported 41648 injuries in 2016, and stated that the index of accident incident rate was 2, 5 and the absolute highest number of injuries (26 145) was reported mainly in elementary schools. These injuries included mainly arm or hand injuries (47, $4 \%)$, leg and feet injuries (30,6\%) and head injuries (12, $3 \%)$. The highest amount of injuries was reported to happen during PE lessons (35, 3 \%). The vast majority of school-related injuries are prevented by teachers, early prevention and the quite safe school environment. Due to this fact there are a very low number of fatal or serious injuries reported in schools. However, it is important to know how to prevent even small injuries in the school environment. Children are very active and environment change is not a sufficient safety measure. Active preventing, meaning teaching about safety on the school premises is an essential part of injury prevention according to the Czech school inspection report (2017). Physically and mentally disabled children are more likely to sustain an injury than regular children due to the decreased motion control and motor skills, psychological disorders, potential side effects of medication used etc. (Sinclair, \& Xiang, 2008; Zhu, Xia, Xiang, Yu, \& Du, 2010; Ramirez, Fillmore, Chen, \& Peek-Asa, 2010). Ramires al. (2004) state that disabled children are less able to participate in school activities, games and social events during the school year. During the last several years the accident incident rated of disabled children caught attention of authorities in the area of general public health, however epidemiology of accident incident rates of children with a handicap is still given only little attention, which is reflected in the low number of studies published in this area (Watier, 2016; Xiang, Stallones, Chen, Hostetler, \& Kelleher, 2005; Bonander, Beckman, Janson, \& Jernbro, 2016).

The research in the area of accident incident rates related to the safe environment has recently become a new independent research area of secondary outcomes of disabilities among individuals with health disabilities. School is the place where children spend the majority of their time during the day. Thus creating a safe school environment and helping schools to ensure safety measures is very complicated. Even accessible places which are equipped with ramps for wheelchairs, widened doors, elevators etc. have some probability of possible injury which a disabled person may sustain when spending time in such an environment. Speech limitations, cognitive function deficits, motor function disorders can complicate processing of physical risk taking in schools (Petridou, Kedikoglou, Andrie, Farmakakis, Tsiga, \& Angelopoulos, 2003; Ramirez, Peek-Asa, \& Kraus, 2004; Wolfdieter, 2013). E. Petridou al. (2003), for example points to the alteration of epidemiological profile of injuries sustained by disabled children, on the other hand the author states, that the exposure to possible risk of injury is statistically reduced due to the mobility limits and 
expected higher carefulness of such individuals. Designing of a suitable and safe school environment is also very complicated because of different individual functional states of each disabled child, of course, disabilities differ in many aspects from person to person (Lee, Harrington, Chan, \& Connors, 2008). There are several studies focused on the unintentional injury rates of children and youth with attention deficit disorder. Ruiz-Goikoetxea al. began conducting a systematic meta-analysis of nonintentional injuries of children with ADHD in 2017.

Risk of unintentional injuries in children and adolescents with ADHD protocol and protocol for a systematic review and meta-analysis point to the fact, and those available academic sources include mainly case studies which reflect only one type of injury, such as, dental, fractures of a specific segment or burns. The main limitation of such case studies is the dependence on small data samples which is the case for our study as well. However, all studies in the field have a tendency to give results of higher accident incident rates among ADHD children. The study titled: The risk of injuries in children with Attention deficit-hyperactivity disorder (ADHD) in England, state that there was a 28\% higher probability of bone fracture among ADHD children than among children without ADHD diagnosis. When it comes to burn rates, ADHD children were evaluated to be at twice the risk of sustaining a burn injury than others and poisoning rates were even four times higher than compared with children without ADHD in the control group (Prasad, Sayal, West, \& Kendrick, 2016).

In order to solve prevention issues of accident incident rates of children with ADHD even at pre-school level, we should mention a study by W.C.H . Chien al. (2017) which focused on the risk of injury in adults with attention-deficit hyperactivity disorders under the subtitle: A nationwide, matched-cohort, population-based study authors point at other studies being in agreement, that ADHD children diagnosed in early stages of development are at higher risk of nonintentional injury and that is why these children should be regarded as main candidates in injury prevention campaigns in pre-school programs. Other than this, hazardous behaviour of ADHD children is closely connected to behavioural disorders and antisocial disorders may also contribute to a higher probability of injury. Such factors can also increase the risk of injury among adults with ADHD, although to prove such hypothesis, more studies in this field are needed. School is then the ideal environment for epidemiology research. The school environment offers wide and well-defined groups, is to an extent a quite controlled environment suitable for studying risk factors (Ramirez, Peek-Asa, \& Kraus, 2004). The National Health Interview Survey has found that children with disabilities experienced higher amounts of injuries than other children. Also the survey stated that schools were next in line after homes in the ratings of places with the highest number of injuries (Ramirez, Fillmore, Chen, \& Peek-Asa, 2010). Our study also verified the increased risk of injury among ADHD children in schools. The results of all mentioned published studies underline the necessity to support injury prevention awareness and prevention programs which focus mainly on children with disabilities. 


\section{CONCLUSION}

Most children are diagnosed with ADHD during compulsory school years, more specifically, between $6^{\text {th }}$ and $9^{\text {th }}$ grade. M. Goetz and P. Uhlíková (2010) State that after the primary school initiation, the ADHD symptoms are gradually occurring and issues coming out of them are increasing in intensity over time. Children with attention deficit represent a risk of injury mainly due to the non-structured time schedule e.g. activities during breaks between lessons. Their behaviour during breaks has to be autoregulated by children themselves without supervision or directives. Transport between classrooms, locker rooms, breaks, gap lessons, waiting for the school bus and many other situations then require such social behaviour in which these children are not very skilled at. Based on the research in the area worldwide, the results verified the injury prevalence among children with ADD/ ADHD which is higher than among non affected children. The research question was, as follows: What are the Accident incident rates of children with attention deficit disorders in comparison with non-diagnosed children in public elementary schools? We also established a working hypothesis: The risk of accidents in the school environment will differ between children with attention deficit disorders and regular children. The results of our study verify that children with ADHD are at higher risk of sustaining an injury in school environment. The data collection took place between September 2016 and June 2017. During this time period, out of 100 given questionnaires filled by ADHD children, the result show $49 \%$ of them experienced an injury in school and children without ADHD diagnosis reported injury in only $26 \%$ of cases, which means that roughly every second child with a Attention Deficit Hyperactivity Disorder experienced an injury some time during the school year during class, whereas among neurotypical (normal) children this ratio would refer to every fourth child. The analysis of the data undeniably point to the necessity of raising awareness of the injury risks in school environment and support prevention programs, which would focus mainly on children with different kinds of disabilities.

\section{ETHICAL COMMITTEE APPROVAL}

The first stage of the study included asking school authorities and principals with a formal request for research collaboration. Information about the study itself were given to each teacher during school board (council) meetings, because the questionnaires were mostly filled by teachers who were direct witnesses of an injury, or he or she was the one who filled-in an injury into the school repot book. During the research children were not traumatized in any way. If an injury occurs in school environment, it is always recorded in detail into the book of accident records and the child is then treated accordingly. If there is a child with attention deficit disorder who sustains and injury, it is simply recorded into the school records the same way, as any other injury, with the additional information of reporting "injury of a child with attention deficit disorder".

Parents of children participating in this study were approached by teachers of individual schools and informed about the research. Those, who did not agree for 
their children to be participants, were excluded from the data sample. Parents who agreed were given a form of agreement of recording sensitive data (name, diagnosis, gender, school year) for research purposes. After the study parents were given access to their child data records. Based on the previously mentioned facts, the ethical committee negotiated the research design and approved its realisation. The main reason of approval: This study works with a sensitive group of children whose protection is adequately ensured.

\section{REFERENCES}

1. Bonander, C., Beckman, L., Janson, S., \& Jernbro, C. (2016). Injury Risks in Schoolchildren With Attention-deficit/Hyperactivity or Autism Spectrum Disorder: Results from Two School-Based Health Surveys of 6- to 17-year-old Children in Sweden. Journal of Safety Research. 58, 49-56.

2. Goetz, M., \& Uhlíková P. (2009). ADHD - Porucha pozornosti s hyperaktivitou: př́ručka pro starostlivé rodiče a zodpovědné učitele [ADHD - Attention Deficit Hyperactivity: Handbook for Careful Parents and Responsible Teacher]. Praha: Galén.

3. Chien, W.C.H., Chung, C.H.H., Lin, F.H., Yeh, C.H.B., Huang, A.Y., Lu R.B., Chang, H.A., Kao, Y.C.H., Chiang, W.S., Chou, Y.C.H., Tsao, C.H.H., Wu, Y.F., \& Tseng, N.S. (2017). The risk of injury in adults with attention-deficit hyperactivity disorder: A nationwide, matched-cohort, population-based study in Taiwan. Research in Developmental Disabilities. 65, 57-73. doi: https://doi. org/10.1016/j.ridd.2017.04.011

4. Jucovičová, D., \& Žáčková, H. (2010). Neklidné a nesoustředěné dítě ve škole a v rodině. [Restless and Unsettled Child at School and in The Family]. Praha: Grada.

5. Lee L.C.H, Harrington, A., Chan, J.J, \& Connors, S.L. (2008). Increased Risk of Injury in Children With Developmental Disabilities. Research in developmental disabilities. 29, 247-255. doi: https://doi. org/10.1016/j.ridd.2007.05.002

6. Petridou, E., Kedikoglou, S., Andrie, E., Farmakakis, T., Tsiga, A., Angelopoulos, M., et al. (2003). Injuries Among Disabled Children: a Study From Greece. Injury of Prevention. 9(3), doi: 226-230. http://dx.doi.org/10.1136/ip.9.3.226

7. Prasad, V., Sayal, K., \& Kendrick, D. (2016). The risk of injuries in children with Attention deficit-hyperactivity disorder (ADHD) in England. BMJ Open, 22 (2), 122 -130. doi: http://dx.doi. org/10.1136/injuryprev-2016-042156.355

8. Ramirez, M., Fillmore, E., Chen, A., \& Peek-Asa, C.A. (2010). Comparison of School Injuries between Children With and Without Disabilities. Academic Pediatric. 10 (5), 317-322. doi: http:// dx.doi.org/10.1016/j.acap.2010.06.003

9. Ramirez, M., Peek-Asa, C., \& Kraus, J.F. (2004). Disability and Risk of School Related Injury. Injury Prevention. 10(1), 21-26. doi:10.1136/ip.2003.002865

10. Ruiz-Goikoetxea, M., Cortese, S., Aznarez-Sanado, M., Maggalon, S., O Luis, E., Zallo, NA, De Castro-Manglano, P., Sutullo, C., \& Arrondo, G. (2017). Risk of unintentional injuries in children and adolescents with ADHD and the impal of ADHD medications: protocol for a systematic review and meta-analysis, BMJ Open, 7, 1 - 11. doi: http://bmjopen.bmj.com/content/7/9/e018027

11. Sinclair, S. A., Xiang, H. (2008). Injuries Among US Children With Different Types of Disabilities, American Journal of Public Health. 98(8), 1510 - 1516. doi: 10.2105/ AJPH.2006.097097

12. Watier, L. (2016). Ubylo žáků se zdravotním postižením [Fewer Pupils With Disabilities] Statistika\&My. $6(5), 28-29$.

13. Wolfdieter, J. (2013). ADHD: Porucha pozornosti s hypeaktivitou - Rádce pro rodiče a učitele [ADHD: Attention Deficit Hypeactivity - Counseling For Parents and Teachers] Brno: Albatros Media.

14. Xiang, H., Stallones, L., Chen, G., Hostetler, S.G., \& Kelleher, K. (2005). Nonfatal Injuries Among US Children with Disabling Conditions. American Journal of Public Health. 95(11), 1970 - 1975.

15. Zhu, H.P., Xia, X., Xiang, H.Y., Yu, C.H., Du, Y.K. (2012). Disability, home physical environment and non-fatal injuries among young children in China. PLoS One. 7(5), e37766. doi: https://doi. org/10.1371/journal.pone.0037766. 